Article

\title{
Development of an Autonomous Electric Robot Implement for Intra-Row Weeding in Vineyards
}

\author{
David Reiser ${ }^{1, *}{ }^{\mathbb{D}}$, El-Sayed Sehsah ${ }^{2}$, Oliver Bumann ${ }^{1}$, Jörg Morhard ${ }^{1}$ and \\ Hans W. Griepentrog ${ }^{1}$ \\ 1 Institute of Agricultural Engineering, Hohenheim University, Stuttgart 70599, Germany; \\ oliver.bumann@uni-hohenheim.de (O.B.); morhardj@uni-hohenheim.de (J.M.); \\ hwgriep@uni-hohenheim.de (H.W.G.) \\ 2 Department of Agricultural Engeenering, Faculty of Agriculture, Kafrelsheikh University, \\ Kafrelsheikh 33516, Egypt; sehsah_2000@yahoo.de \\ * Correspondence: dreiser@uni-hohenheim.de; Tel.: +49-711-45924552
}

Received: 21 November 2018; Accepted: 4 January 2019; Published: 10 January 2019

\begin{abstract}
Intra-row weeding is a time consuming and challenging task. Therefore, a rotary weeder implement for an autonomous electrical robot was developed. It can be used to remove the weeds of the intra-row area of orchards and vineyards. The hydraulic motor of the conventional tool was replaced by an electric motor and some mechanical parts were refabricated to reduce the overall weight. The side shift, the height and the tilt adjustment were performed by linear electric motors. For detecting the trunk positions, two different methods were evaluated: A conventional electromechanical sensor (feeler) and a sonar sensor. The robot performed autonomous row following based on two dimensional laser scanner data. The robot prototype was evaluated at a forward speed of $0.16 \mathrm{~ms}^{-1}$ and a working depth of $40 \mathrm{~mm}$. The overall performance of the two different trunk detection methods was tested and evaluated for quality and power consumption. The results indicated that an automated intra-row weeding robot could be an alternative solution to actual machinery. The overall performance of the sonar was better than the adjusted feeler in the performed tests. The combination of autonomous navigation and weeding could increase the weeding quality and decrease power consumption in future.
\end{abstract}

Keywords: autonomous robot; agriculture; viticulture; electric weeder; sonar; intra-row; under-vine; row following

\section{Introduction}

The impact of chemical pesticides became an important global issue for the sustainability of the food production system. More and more organic food is produced and has become popular all over the world. One reason for the use of chemical pesticides is to reduce weeds, as they can be responsible for high yield losses [1]. However, to leave them untreated is not an option, as weeds could be responsible for a decrease of up to $40 \%$ of yield [2,3]. The importance of mulching and weeding in vineyards was already conducted in different studies. It was proclaimed that organic mulching was the most sustainable practice for yearly vine production [4]. In order to reduce chemical weed control, mechanical weeding approaches are promising alternatives. Mechanical weed control can be conducted between the tree/crop rows (inter-row) and within the tree/crop rows (intra-row). The main challenge of mechanical weed control is the realization at the intra-row area [5]. Weeding close to the crop/trunk and the use of intra-row weeding tools needs a very accurate steering for not damaging the crop/trunk [6]. Therefore, accurate guidance systems are needed. During the last decades, navigation has been improved by the use of new automatic row guidance systems using feelers, Global Navigation 
Satellite Systems (GNSS), distance sensors and cameras [7-9]. The development of these technologies has created wide opportunities for weed management and may become a key element of modern weed control [10]. Anyhow, in order to increase the selectivity of the weed control and reduce the crop plants damage, intelligent autonomous weeding systems are needed. Identifying individual weeds and crops is possible by the use of mechanical feelers, GNSS coordinates, sonar sensors, laser scanners, or cameras [11-14]. Automation offers the possibility to determine and differentiate crops from weeds and at the same time, to remove the weeds with a precisely controlled device. Automated weeding implements developed [15-18], provide examples of how the control of mechanical weeding can be performed. Real-time weeding robots have the potential to control intra-row weeds plus reduce the reliance on herbicides and hand weeding $[19,20]$.

For reducing labor costs of mechanical weed control the whole task has to be automated. This approach could result in self-guided, self-propelled and autonomous machines that could cultivate crops with minimal operator intervention. Weeding robots can improve labor productivity, solve labor shortage, improve the environment of agricultural production, improve work quality, reduce energy input, improve resource management, and help farmers to change their traditional working methods and conditions [21]. Introducing self-governing mobile robots in agriculture, forestry and landscape conservation is dependent on the natural environment and the structure of the facilities. The solution proposed is the use of little and light machines, like unmanned vehicles that are self-propelled, autonomous and low powered [22]. Mobile robots must always be aware of its surroundings such as unpredicted obstacles [23]. To this scope, real-time environment detection could be performed using different sensor systems.

There were several autonomous machines and robots developed in the past [24]. Zhang et al. investigated the performance of a mechanical weeding robot [25]. They used machine vision to locate crop plants and a side shift mechanism to move along the crop rows. The intra-row weeds were controlled by moving hoes that could open and close to prevent damage to crop plants. Another study by Nørremark et al. developed an automatic GNSS-based intra-row weeding machine using a cycloid hoe [13]. The weeder used eight rotating tines, which could be released to tolerate crop plants. This automated weeding system mainly used Real Time Kinematic (RTK)-GNSS to navigate and control the side-shifting frame plus a second RTK-GNSS to control the rotating tines. Astrand and Baerveldt investigated the performance of a vision-based intra-row robotic weed control system [16]. The robotic system implemented two vision systems to guide the robot along the crop row and to discriminate between crops and weed plants. The weeding tool consisted of a rotating wheel connected to a pneumatic actuator that lifted and lowered the weeding tool to tolerate crop plants. Robots for weeding in vineyards were also developed, mainly focusing on trunk detection $[26,27]$. Weeds in vineyards can cause significant reductions in vine growth and grape yields [11]. Conventional control methods rely on herbicide applications in the vine rows and the area between them (middles), or a combination of herbicide strip application in the vine row and mowing or disking of the middles [28]. For a mobile robot to navigate in between the vine or tree rows, it must detect the position of the rows first, by means of detecting the trunks. The complete integration of an under-vine rotary weeder in an autonomous robot system for active intra-row weeding in vineyards and orchards was not done until now.

The overall goal of the current research was to develop and test the performance of a rotating electrical tiller weeder mechanism, built for automated intra-row weeding for vineyards. The system should be integrated in an autonomous robot platform and should be evaluated under controlled soil bin and outdoor conditions. The power requirement of the rotary blades mechanism and the total power for the autonomous robotic machine were of interest. The second interest was to test and compare two control strategies for detecting trunks, using a sonar sensor and a feeler. 


\section{Materials and Methods}

\subsection{Mechanics and Electronics}

An electric tiller head rotary weeder cultivator was manufactured and designed in the laboratory of the Institute of Agricultural Engineering, Hohenheim University and was mounted to an autonomous caterpillar robot called "phoenix" [14] (see Figure 1). The prototype electric rotary weeder was built up using a rotary weeder from Humus Co. called "Humus Planet" (Humus, Bermatingen, Germany). This tool originally operated with a hydraulic motor and was redesigned to get driven by an electric DC motor. A 1 kW 48DC brushed motor model ZY1020 (Ningbo Jirun Electric Machine Co.,Ltd., Nigbo, China) was used. The motor had a nominal torque of $2 \mathrm{Nm}$ and a rated speed of $3200 \mathrm{rpm}$. The motor was mounted using a gearbox reducing with 30:1 ratio to produce a nominal torque of $60 \mathrm{Nm}$ and a motor speed of $106 \mathrm{rpm}$ at the rotary weeder. The gearbox was directly connected with a drive shaft to the rotary weeder. The motor and the gearbox were connected using a $\mathrm{v}$-belt. The developed rotary weeder was fixed on a metal bar together with the drive unit.

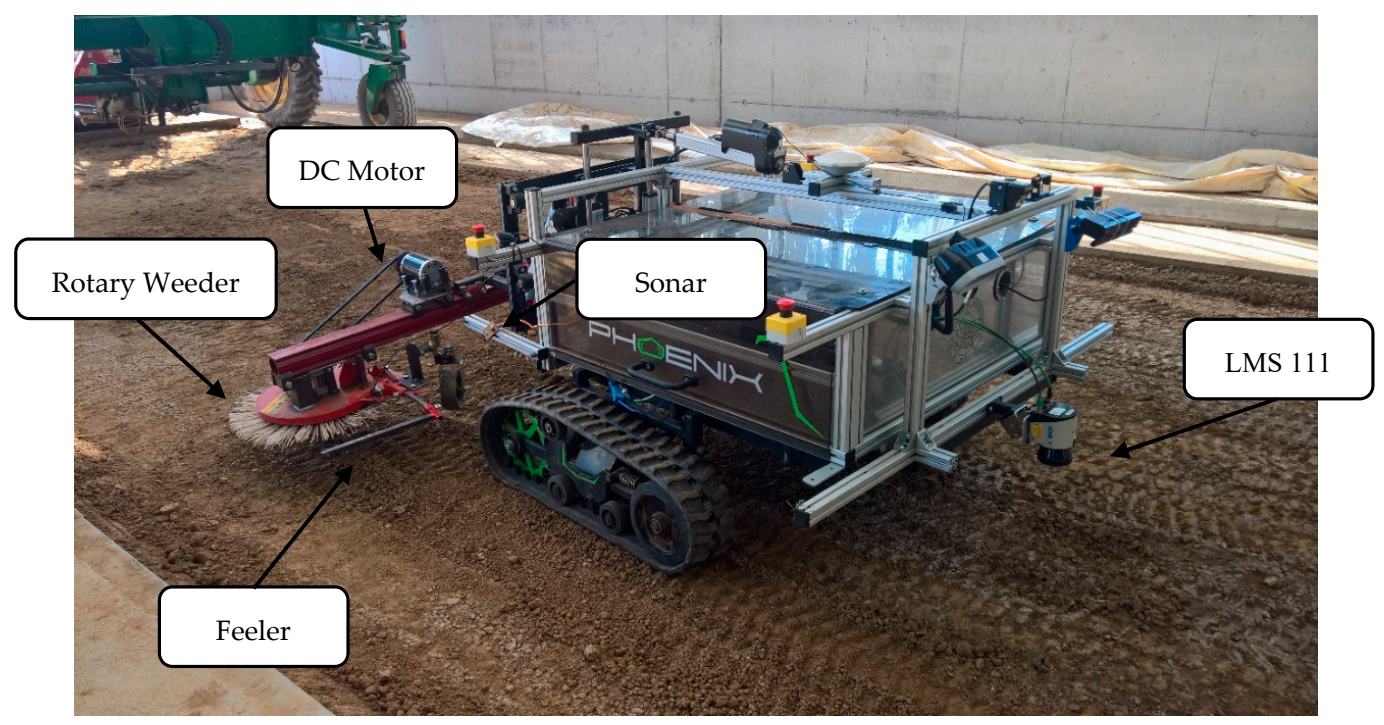

Figure 1. Autonomous robot called "phoenix" with attached rotary weeder implement and sensors.

The whole implement was attached to the robot using a coupling triangle. The implement could be moved up, down, left, right and could be tilted with the help of three Linak LA36 actuators (Linak, Nordborg, Denmark). They were capable of creating a pull/push force between $1700 \mathrm{~N}$ and $4500 \mathrm{~N}$. This was sufficient to move the implement under all circumstances. The robot system was driven by two brushless motors HBL5000 (Golden Motor Technology Co., Ltd., Jiangsu, China), creating a maximum driving power of $10 \mathrm{~kW}$, sufficient to move the $500 \mathrm{~kg}$ weight of the robot plus implement even in harsh terrain. The two times $80 \times 15 \mathrm{~cm}$ belt system of the phoenix minimized soil compaction and provided enough grip and pull force for mechanical weeding. The width of the robot was $1.70 \mathrm{~m}$. The implement could move $30 \mathrm{~cm}$ side wards, to move the tool inside the crop row. The power of the whole robot system was provided by batteries, with a nominal voltage of $48 \mathrm{~V}$ and $304 \mathrm{Ah}$. The implement motor was powered by a motor controller Model LB57 (Yongkang YIYUN Elektronic Co., Ltd., Zhejiang, China). The drive motors were controlled by two ACS48S motor controllers (Inmotion Technologies AB, Stockholm, Sweden). The whole robot was controlled and programmed with an embedded computer with i5 processor, 4 GB Ram and 320 GB disk space.

\subsection{Sensors}

For following the tree and vine rows, a LMS 111 (Sick, Waldkirch, Germany) 2D laser scanner was used [29]. The mounting of the scanner was in the front of the vehicle to enable a security stop if an 
obstacle appeared in front of the robot. Additionally, there were four security switches attached to the robot, disabling the drive and implement motors in case of an emergency. For gaining the heading and traveled distance, an Inertial Measure Unit VN100 (VectorNav, Dallas, TX, USA) was fused with the hall sensor information of the drive motors [30]. The traveling distance was defined by the hall sensors, and the heading was estimated with the IMU. For guiding the implement, two different methods and sensors were tested. The first method used a standard feeler, a modified version of the original feeler of the rotary weeder. As the second method, a sonar sensor pico $+100 / \mathrm{U}$ (microsonic, Dortmund, Germany) was used to detect the trunks [31]. This sensor was used to detect the trunks, because it could be placed at any position at the robot. The signal could directly replace the input signal of the feeler without any additional software changes.

The specifications of the different sensor systems can be found in Table 1. The data of the feeler and the sonar sensor were digitalized using an analog digital converter from RedLab 1208LS (Meilhaus Electronic, Alling, Germany). This information could be used to send control signals to the implement and the linear motors.

Table 1. Sensor specifications of the used sensors of the robot.

\begin{tabular}{ccc}
\hline Sensor & Specification & Value \\
\hline LMS 111 [29]: & Operating range: & $0.5 \mathrm{~m}$ to $20 \mathrm{~m}$ \\
& Field of view/scanning angle: & $270^{\circ}$ \\
& Data rate: & $25 \mathrm{~Hz}$ \\
& Angular resolution: & $0.5^{\circ}$ \\
& Systematic error: & $\pm 30 \mathrm{~mm}$ \\
& Statistical error $(1 \sigma):$ & $12 \mathrm{~mm}(0.5-10 \mathrm{~m})$ \\
\hline Pico + 100/U [31]: & Operating range: & 0.12 to $1.0 \mathrm{~m}$ \\
& Field of view/scanning angle: & $22^{\circ}$ \\
& Data rate: & $10 \mathrm{~Hz}$ \\
& Distance measurement accuracy: & $\pm 1 \%$ \\
\hline VN100 [30]: & Data rate: & $40 \mathrm{~Hz}$ \\
& Angular resolution: & $0.05^{\circ}$ \\
& Accuracy heading: & $2.0^{\circ}$ \\
& Accuracy pitch/roll: & $1.0^{\circ}$ \\
\hline
\end{tabular}

\subsection{Software}

The control and data logging of the whole robot system and implement was programmed using ROS Indigo-middleware [32]. The embedded computer ran under Ubuntu 14.04. All parts of the guidance software were programmed using $\mathrm{C} / \mathrm{C}++$. All data created were pushed to a so called "topic" which could be time stamped and recorded with the ROS system. This data could be analyzed for evaluating the power consumption, the movement of the robot and the implement behavior. The movement and the transformations between the robot base and the implement was performed using the Transform Library of ROS [33].

The guidance of the robot was performed with the use of 2D laser scanner data. First the data were converted to Cartesian coordinates and were filtered with a range filter of $5 \mathrm{~m}$. The points were separated into two clusters, one for the left and one for the right side of the row. This was done by separating all points exactly at the laser scanner position into two point clouds (left and right). Afterwards the points were filtered using a Euclidean Clustering method using a distance threshold of $1.5 \mathrm{~m}$. The resulting cluster with the highest point cloud number was estimated as the row point cluster. This clustering helped to get the row filtering more robust. The resulting points of each side were afterwards used to estimate a best fit line with the use of a RANSAC algorithm [34]. This resulted in two estimated lines, one for each row side. The median of the two resulting lines was used to define the row direction and the next goal point. When one line was missing, or a fixed distance to the row was needed, like in this weeding application, a fixed offset to one side could be set. 
In this application a side offset of $0.15 \mathrm{~m}$ to the right side detected row was used. Therefore, the implement could move $0.15 \mathrm{~m}$ inside the crop row, as the maximum side shift was limited to $0.3 \mathrm{~m}$. The forward speed was controlled by the software and just an active angle adjustment was done based on the line following algorithm of the laser scanner. The robot drive motor controller and the implement motors were controlled with CAN bus signals. The update rate of the motor control was fixed to $10 \mathrm{~Hz}$.

The control of the implement was realized in a separate ROS node, analyzing the values of the switch and the sonar sensor. As soon as the feeler or the sonar detected an obstacle like a trunk, the linear actuator was shifted "inside". When there was no obstacle detected, the actor moved "outside" until the maximum outer position was reached. The robot program could be started and stopped using a basic joystick. There were two different programs available, one using just the sonar value and one the feeler signals. The feeler signal just included a digital signal. The output of the sonar sensor was an analog signal between 0 and $10 \mathrm{~V}$. This sensor output correlated with the object distance, detected by the sensor. As soon as the limit distance of $5 \mathrm{~V}$ was read in the ADC Redlab, a digital input signal was triggered, shifting the actuator "inside".

The height of the implement could be fixed to one depth, or could use the actual motor current of the implement to control the depth dependent on the motor torque. This could help to minimize the necessary force and prevent the rotary tiller weeder to get stuck. In the indoor soil bin, the height was fixed, as the surface was even and without any huge disturbances. In the outdoor tests the adaptive height adjustment variance was used to adjust the implement to the soil surface.

The following Figure 2 shows the ROS-visualization tool "rviz" used to visualize the live data, acquired at the robot system. The robot pose was visualized in real time together with the implement pose, the laser scanner data, the sonar data and the next waypoint the robot wanted to follow. This helped to debug the system while programming and provided feedback to the user.

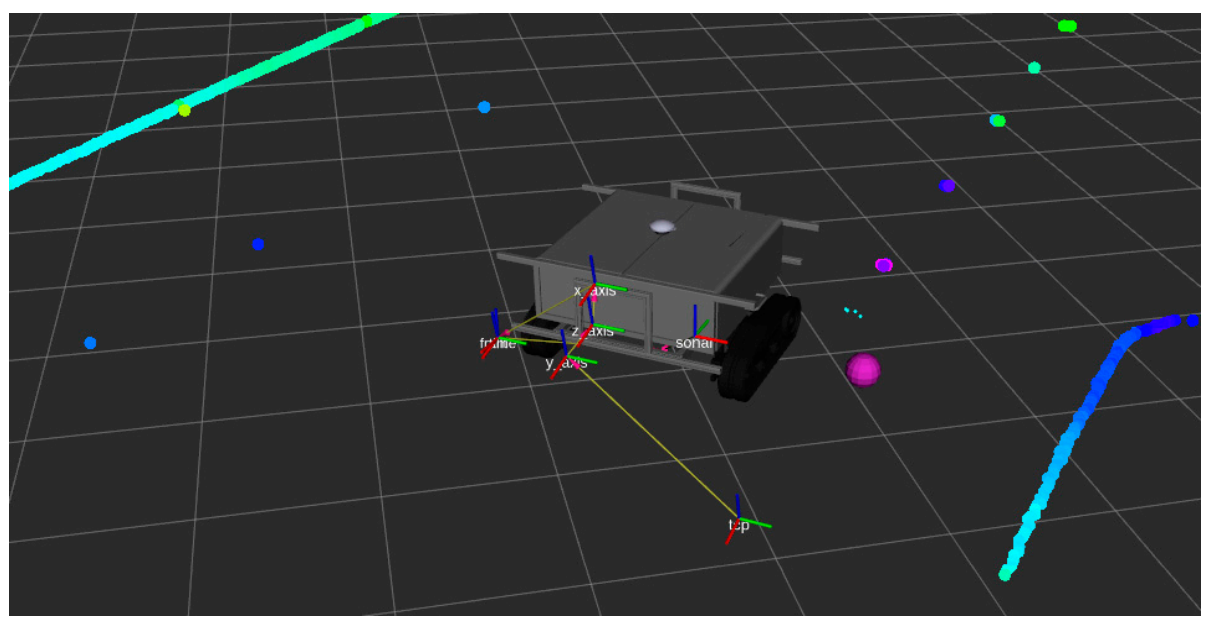

Figure 2. ROS-Software environment visualization "rviz" of robot position, implement position and the laser scanner points (small dots) and sonar data (purple ball).

The tilled area in the vineyard was analyzed by using the open source software ImageJ version 5.22 [35]. For further processing of the gained data, the software Microsoft Excel (Microsoft Corporation, Redmond, WA, USA) was used.

\subsection{Test Environments}

The indoor experiment was performed at the Hohenheim University soil bin laboratory. The indoor soil bin had $46 \mathrm{~m}$ length, $5 \mathrm{~m}$ width and $1.2 \mathrm{~m}$ depth. The mixture of the soil content was $73 \%$ sand, $16 \%$ silt and $11 \%$ clay. The soil was prepared by a rotary harrow, first loosening the soil and afterwards re-compacting the upper soil layer using a flat roller. 22 different plots were 
prepared and the soil was marked and oriented by using poles of wood with the size of $3 \times 3 \times 160 \mathrm{~cm}$. The poles were separated with $1.5 \mathrm{~m}$ distance and simulated the trees/trunks for the indoor test. The total area evaluated for the treatment quality between every two poles was $0.45 \mathrm{~m}^{2}$ (1.5 m length, $0.3 \mathrm{~m}$ row width). This area was divided into 18 rectangles marked on the soil by using chalk. After the experiment, the rectangles with no interaction with the tiller were defined as non-tilled area. Three main soil parameters were recorded for each individual plot. The penetration resistance, soil moisture content and soil shear strength conditions were measured with an H-60 Hand-Held Vane Tester (GEONOR, Inc., Augusta, GA, USA). The specific soil moisture was logged using a TRIME-PICo 64 Time-Domain-Reflectometry sensor (IMKO Micromodultechnik GmbH, Ettlingen, Germany). The penetration force was measured with an Eijkelkamp penetrometer logger (Eijkelkamp, Giesbeek, The Netherlands).

It was decided to use the absolute rotational speed for the implement and a forward speed for the robot of $0.16 \mathrm{~m} \mathrm{~s}^{-1} .11$ plots were treated using a feeler and the remaining 11 plots were treated while detecting the poles with the sonar sensor. The position of the sonar and the feeler was placed $0.5 \mathrm{~m}$ before the weeder, so that the implement could move out of the way even without stopping the robots forward speed. The goal distance between the robot and the row was fixed to $0.15 \mathrm{~m}$ in the row following software. When a pole was detected, the electric actuator shifted the rotary out of the row, to prevent damage to the poles. As soon as the pole was passed, the actuator got shifted back inside the row. The linear motor used for the side shift had a maximum speed of $68 \mathrm{~mm} / \mathrm{s}$ with no load and $52 \mathrm{~mm} / \mathrm{s}$ at maximum load. On average this resulted in a travel speed of $60 \mathrm{~mm} / \mathrm{s}$ of the linear LA36 actuator. As the implement was set up to move $0.15 \mathrm{~m}$ to the intra row area, at least a time difference between pole detection and arrival of the tool of $2.5 \mathrm{~s}$ were needed. As the traveling speed of the robot was fixed to $0.16 \mathrm{~m} / \mathrm{s}$, it was necessary to detect the tree at least $0.4 \mathrm{~m}$ before the implement. For gaining some buffer, the pole detection was set up at a distance of $0.5 \mathrm{~m}$. The time delay for the shifting mechanism was fixed to $2.5 \mathrm{~s}$ in the software to get as close as possible to the poles and therefore to potential trunks. The following Figure 3 describes the mechanical and electrical components of the two control methods using the sonar sensor and the feeler.
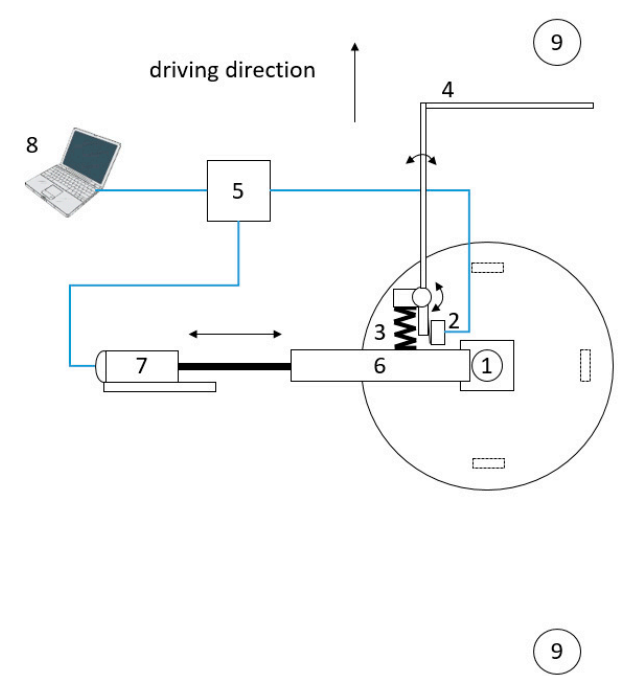

(A)
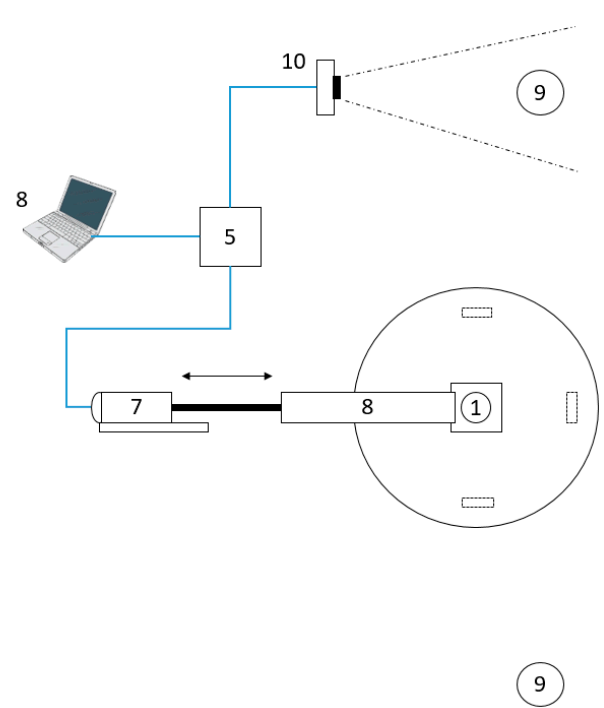

(B)

Figure 3. The two different control methods: (A) Feeler controlled unit and (B) Sonar sensor controlled actuator for the developed autonomous electric weeder. 1-Electric weeder; 2-Switch; 3-Spring; 4-Feeler; 5-Embedded controller; 6-Bar for implement; 7-Linear actuator; 8-PC; 9-Trunks (poles); 10-Sonar sensor. 
For each treatment, the power consumption and the accuracy of the processing procedure were evaluated estimating the treated and the non-treated area. The better control method tested in the indoor laboratory was evaluated at the vineyard of Hohenheim University (48.710115 N, 9.212913 E) on 9 October 2018 (see Figure 4). The following figure shows the two different test areas for the autonomous weeding robot.

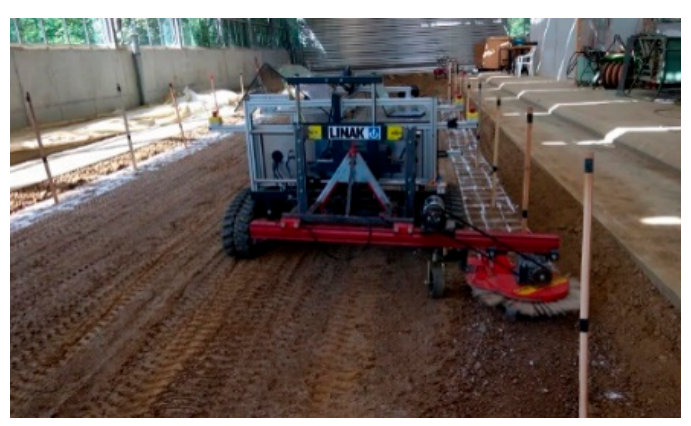

(A)

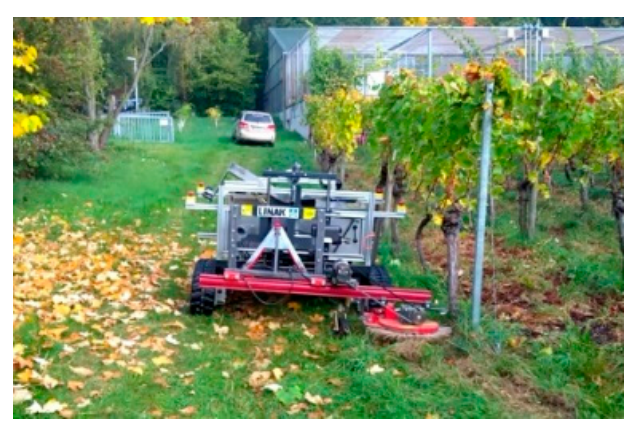

(B)

Figure 4. The two test environments- (A) indoor laboratory and (B) outdoor vineyard.

\section{Results and Discussion}

\subsection{Comparison of Feeler and Sonar}

Over the plots of the indoor trial, the soil moisture varied between $13.1 \%$ and $7.4 \%$ by volume. The shear stress varied between 59 and $82 \mathrm{MPa}$. The penetration resistance varied between 2 and $4 \mathrm{MPa}$ for the depths of the first $10 \mathrm{~cm}$. The detailed results of the soil physical properties for the laboratory test can be found in Table 2.

Table 2. Soil physical properties for the evaluation of the sonar and the feeler method in the soil bin and the resulting tilled area (indoor laboratory test).

\begin{tabular}{ccccccc}
\hline Plot & Sensor & $\begin{array}{c}\text { Soil Penetration, } \\
\text { MPa (0-10 cm Depth) }\end{array}$ & $\begin{array}{c}\text { Moisture } \\
\text { Vol. } \%\end{array}$ & $\begin{array}{c}\text { Soil } \\
\text { Temp., }\end{array}{ }^{\circ} \mathbf{C}$ & $\begin{array}{c}\text { Shear Stress, } \\
\text { MPa }\end{array}$ & $\begin{array}{c}\text { Tilled Area, } \\
\text { \% }\end{array}$ \\
\hline t1 & Sonar & 2 & 13.8 & 20.1 & 61.5 & 94 \\
t2 & Sonar & 2 & 12.7 & 20.4 & 61 & 83 \\
t3 & Sonar & 3.8 & 9.09 & 20.8 & 61 & 89 \\
t4 & Sonar & 4 & 9.7 & 20.9 & 59 & 100 \\
t5 & Sonar & 3 & 8.8 & 21 & 60.5 & 89 \\
t6 & Sonar & 2 & 7.4 & 21.3 & 56 & 94 \\
t7 & Sonar & 2 & 13.2 & 21.9 & 60.5 & 72 \\
t8 & Sonar & 2.5 & 9.8 & 22 & 69.5 & 89 \\
t9 & Sonar & 2.5 & 11.5 & 22.2 & 66.5 & 61 \\
t10 & Sonar & 2.2 & 8.8 & 22.4 & 67.5 & 83 \\
t11 & Sonar & 2.4 & 9.5 & 22.5 & 68 & 50 \\
t1 & Feeler & 3.8 & 10.1 & 22.6 & 62 & 50 \\
t2 & Feeler & 3 & 11.9 & 22.7 & 66 & 61 \\
t3 & Feeler & 3.5 & 12.07 & 22.9 & 79.5 & 61 \\
t4 & Feeler & 2.5 & 13.1 & 23 & 82 & 94 \\
t5 & Feeler & 4 & 9.8 & 23.6 & 70 & 78 \\
t6 & Feeler & 4 & 8.8 & 23.7 & 81 & 78 \\
t7 & Feeler & 4 & 9.5 & 24 & 70 & 56 \\
t8 & Feeler & 4 & 9.7 & 24 & 73 & 44 \\
t9 & Feeler & 3.5 & 10.07 & 24 & 75 & 78 \\
t10 & Feeler & 4 & 9.7 & 24.8 & 79 & 56 \\
t11 & Feeler & 3.8 & 9.7 & 24.8 & 79 & 61 \\
\hline
\end{tabular}




\subsection{Efficiency of the Control Algorithm}

The percentages of the tilled area between the poles (trunks) were used as parameters to indicate the efficiency of weed control in the current study. Table 2 indicates that the sonar treatment performed better than the feeler. Only at the plots $\mathrm{t} 9$ and $\mathrm{t} 11$ the feeler performed better than the sonar. In all other plots sonar performed equal or better compared to the feeler solution. The overall performance of both methods was at least over $50 \%$ of the intra-row area, at some plots reaching a tilled area of almost $100 \%$. The average of the tilled area for the feeler was $65 \%$ and for the sonar it was $82 \%$.

The results of the tilled area indicated a high success rate of both methods. However, the sonar control method outperformed the feeler control. One reason for this was that the sonar signals of the poles could directly be converted to a control message. The feeler sometimes got stuck at the poles for some seconds, causing wrong signals to the actuator and made it hard for the software to define the exact pole position. Additionally, the long lever of the feeler caused vibrations, sometimes triggering the switch even when there was no pole. With no other disturbances e.g., of weeds and branches, the sonar worked reliably and without any failure. Therefore, it was suggested, to test this control method under outdoor conditions later on.

The signals from the sonar sensor over the travelled distance in the soil bin can be seen in the following Figure 5. The gained signals showed a peak at the pole positions. At the beginning the sonar values hit the edges of the poles, causing wrong distance signals. This effect could be seen at both sides of the poles. However, the minimum value of the sticks was quite accurate in distance and position. The signals always formed small peaks with similar values. This shape could be used for further filtering of the exact trunk positions in the future and separate high weed spots from trunks. All poles triggered at least one signal of less than $0.5 \mathrm{~m}$ distance, which triggered the side shift of the implement. Therefore, the sonar could detect all poles at the indoor test.

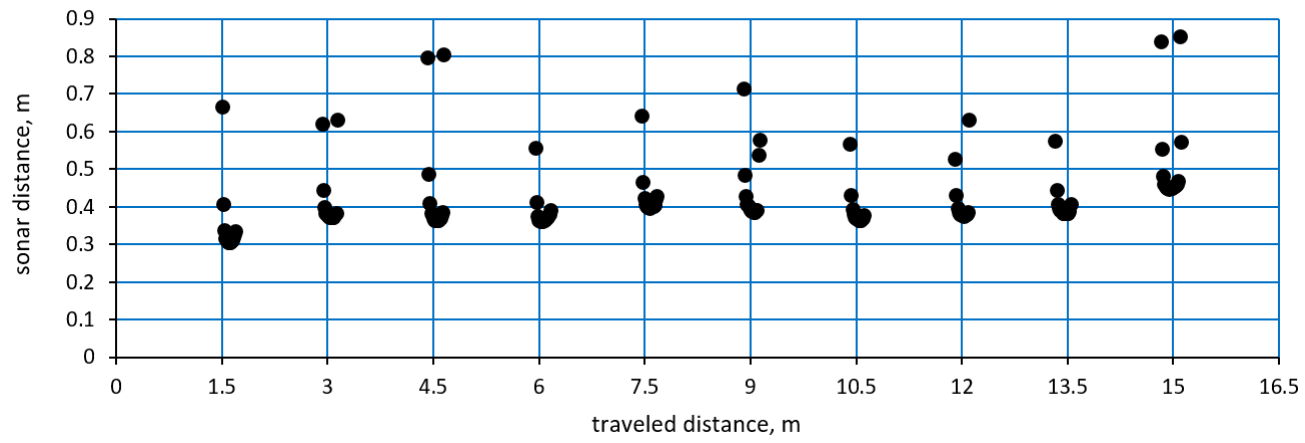

Figure 5. Sonar values detected at the indoor test at the laboratory (soil bin).

In the following outdoor test just the sonar detection was evaluated. Figure 6 shows the sonar detections based on the test in the vineyard of Hohenheim University. In this case the trunks were not spaced out evenly like in the indoor tests. Sometimes individual trunks were missing, or were closer together (less than $0.5 \mathrm{~m}$ ), causing that in this case the intra-row area could not be entered by the tilling device. Additionally, there were shoots and weeds causing disturbances. However, with small height adjustments of the sonar sensor, the system worked well in the outdoor vineyard. The linearity of the row was not given, because of curved trunks, as they were not in a straight line as the wooden poles.

However, all vines were successfully detected, causing no issues with hitting the vines basal area with the implement or similar. But the within-row spacing of the vines was not always suitable for the $0.3 \mathrm{~m}$ diameter electric weeder head, as there was not enough space to enter the intra row area between some trunks. Some of them were close to $0.5 \mathrm{~m}$ distance, causing the system to stay outside of the crop row. Using different sizes of weeder heads would solve this issue. At the spots with bigger gaps, the system performed well and did not cause any problems at all. When analyzing the tilled area 
of the outdoor test using the ImageJ software, the min value reached $57 \%$, the max values $98 \%$ of the tilled area. Areas where the tiller head could not enter were excluded from the analysis.

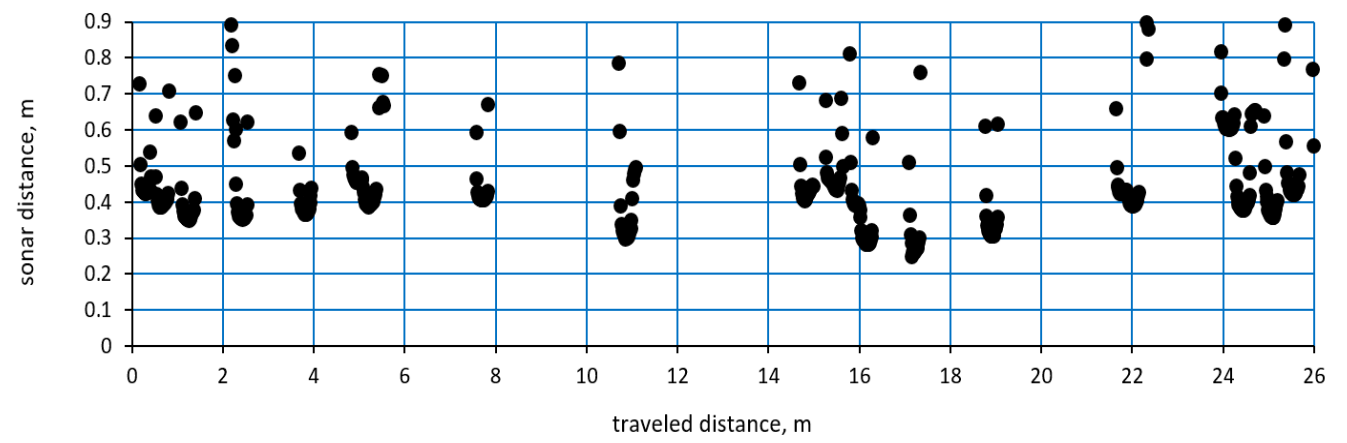

Figure 6. Sonar values detected at the outdoor test (vineyard).

It could be shown, that the outdoor test did perform well under the given circumstances. However, the environment was not sloped, which could bring more issues to the trunk detection. At high angles, shoots and leaves could hang more into the area of the sonar sensor. The automatic trunk detection would work in ordered and well cultivated vineyards. More complex examples would need an additional tree detection system like a laser scanner or camera, which could filter out the sonar values depending on the environment and context. Additionally, the trajectory of the implement could be planned dependent on the robot forward speed. This could make a more flexible path planning possible. However, the tilled area and the detection rate of the system were sufficient for the evaluated test area.

\subsection{Power Requirement for the Autonomous Robot}

The maximum and average power requirement for the implement guidance, actuator motor and belt drive of the autonomous robot is shown in the following Figure 7. In the indoor test, the power consumption increased with higher soil penetration resistance and shear stress. The overall power consumption for the implement was smaller than in the outdoor test. Here, an additional factor was the vegetation layer of weeds, which caused higher power consumption. Because of the implemented algorithm for limiting the working depth depending on the implement motor current, the power consumption peaks in the outdoor test were smaller than in the indoor test. When the soil in the indoor experiment would be compacted more, this difference between indoor and outdoor power consumption for the implement could be equalized.

In all tests the right drive motor of the robot needed more power than the left one. This was quite logical, as the implement was attached to the right side of the robot. The inertial forces of the tiller caused the robot to move to the right. To overcome this momentum, the row follower sent correction signals to the drive motors, forcing the right motor to consume more current. This effect could be seen at all performed tests. In the outdoor experiment, the slope of the tested area was not completely horizontal, causing higher power consumption for the drive motors. The overall power consumption of the machine was $1.8 \mathrm{KW}$ in the soil bin and $2.2 \mathrm{~kW}$ in the outdoor field experiment. This would allow this machine with the given battery power to work around $8.1 \mathrm{~h}$ and $6.6 \mathrm{~h}$ depending on the slope and weed density. With a fixed speed evaluated in the experiments, the system could perform an intra-row weeding of $500 \mathrm{~m} / \mathrm{h}$.

When comparing the power consumption of the whole machine with the official power requirement provided by the rotary tiller manufacturer, the energy reduction is immense. The official power requirement for the tiller was set up with $8.1 \mathrm{~kW}$ by the company. Comparing the power consumption of the whole robot, the savings are more than $5.9 \mathrm{~kW}$, meaning a $73 \%$ energy reduction. When we just compare the attachment, a $1 \mathrm{~kW}$ motor was enough to drive the implement in the performed experiments. When driving the robot system in a sloped environment, the power 
consumption of the drive motors would increase. However, it is expected, that the power consumption of the actuator would not differ in sloped environments.

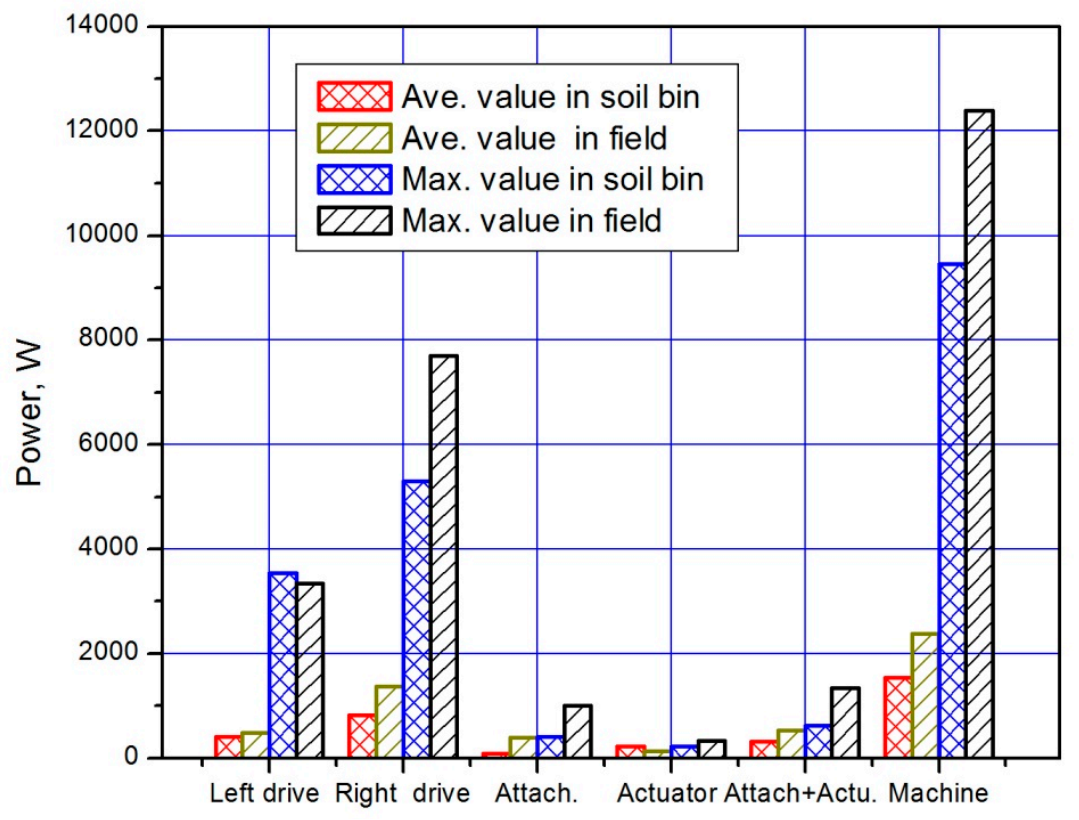

Figure 7. Overall power consumption of the robot for the weeding task.

\subsection{Outlook}

It could be shown that with an electrical implement a high power reduction could be possible, even when using commercial weeding tools. Combined with autonomous robots, this system could be highly energy efficient and sustainable. However, the system could be improved in the future. When using a higher speed for the linear side shift control, the overall speed of the machine could be increased, depending on the rotary speed of the rotary tiller and the side shift performance. Additionally, the tillage quality of the system could be increased, when the robot would stop at each trunk, to move the rotary weeder out of the row. Afterwards the robot could move a little bit forward and move the tool back into the row as soon as the trunk has passed. This would result in a rectangular trajectory, just excluding the trunk. Between the trunks, the speed could be increased until the next trunk is detected.

A different solution for detecting the trunks could be to use the information of the navigation laser scanner in front of the robot. Together with the odometry value, the software could increase the accuracy and plan the best trajectory for the implement based on speed, trunk spacing and weed density. This could help optimize path and work quality for weeding tasks in vineyards and orchards. In combination with a feeler or a sonar sensor this information could be filtered and optimized. This could help to increase the robustness and to not be disturbed from shoots and higher weeds.

\section{Conclusions}

An autonomous tiller weeder for intra-row weeding in vineyards was developed and tested at the University of Hohenheim. The system was built up using a commercial rotary tiller weeder. It was mounted on a mobile robot platform. For the side shift of the system, linear electrical motors were used. The trunk detection was performed with two different methods, using a feeler and a sonar. Both methods performed well and did not harm any trunks. The overall tilled area between the trunks with the sonar was higher than with the feeler, caused by vibrations and the design of the feeler. The autonomous row following based on the laser scanner enabled the machine to follow the rows accurately. The energy consumption of the whole system was evaluated. It could be shown that 
electrical driven machines could perform autonomous weeding in vineyards, which is energy efficient. Therefore, autonomous intra-row weeding machines could save energy and time for workers.

Author Contributions: The experiment planning was done by the first and second author. The programming of the software was done by the first author. The writing was performed by the first, the second and fourth author. The experiments were conducted by the first, second and third author. The first and second author analyzed and processed the data. The mechanical development of the frame and design was performed by the first and the third author. The whole experiment was supervised by the fourth and fifth author.

Funding: This research received no external funding.

Acknowledgments: The project was conducted at the Department for Technology in Crop Production at the University of Hohenheim (Stuttgart, Germany). The companies Mädler and Linak supported the development of the robot with materials and actuators. The authors want to thank Nikolaus Merkt for his support in conducting the outdoor experiments in the university vineyard of Hohenheim

Conflicts of Interest: The authors declare no conflicts of interest.

\section{References}

1. Peteinatos, G.G.; Weis, M.; Andújar, D.; Rueda Ayala, V.; Gerhards, R. Potential use of ground-based sensor technologies for weed detection. Pest Manag. Sci. 2014, 70, 190-199. [CrossRef] [PubMed]

2. Andújar, D.; Dorado, J.; Fernández-Quintanilla, C.; Ribeiro, A. An approach to the use of depth cameras for weed volume estimation. Sensors 2016, 16, 972. [CrossRef] [PubMed]

3. Oerke, E.-C. Crop losses to pests. J. Agric. Sci. 2006, 144, 31. [CrossRef]

4. Susaj, L.; Susaj, E.; Belegu, M.; Mustafa, S.; Dervishi, B.; Ferraj, B. Effects of different weed management practices on production and quality of wine grape cultivar Kallmet in North-Western Albania. J. Food Agric. Environ. 2013, 11, 379-382.

5. Bowman, G. Steel in the Field - A Farmer' s Guide to Weed Management Tools; SARE Outreach: College Park, MD, USA, 1997; ISBN 188862602X.

6. Van Der Weide, R.Y.; Bleeker, P.O.; Achten, V.T.J.M.; Lotz, L.A.P.; Fogelberg, F.; Melander, B. Innovation in mechanical weed control in crop rows. Weed Res. 2008, 48, 215-224. [CrossRef]

7. Barawid, O.C.; Mizushima, A.; Ishii, K.; Noguchi, N. Development of an autonomous navigation system using a two-dimensional laser scanner in an orchard application. Biosyst. Eng. 2007, 96, 139-149. [CrossRef]

8. Reiser, D.; Paraforos, D.S.; Khan, M.T.; Griepentrog, H.W.; Vázquez-Arellano, M. Autonomous field navigation, data acquisition and node location in wireless sensor networks. Precis. Agric. 2017, 18, 279-292. [CrossRef]

9. Andújar, D.; Escolà, A.; Rosell-Polo, J.R.; Fernández-Quintanilla, C.; Dorado, J. Potential of a terrestrial LiDAR-based system to characterise weed vegetation in maize crops. Comput. Electron. Agric. 2013, 92, 11-15. [CrossRef]

10. Bajwa, A.A.; Mahajan, G.; Chauhan, B.S. Nonconventional weed management strategies for modern agriculture. Weed Sci. 2015, 63, 723-747. [CrossRef]

11. Gerhards, R.; Oebel, H. Practical experiences with a system of site-specific weed control in arable crops using real-time image analysis and GPS-controlled patch spraying. Weed Res. 2006, 46, 185-193. [CrossRef]

12. Weiss, U.; Biber, P.; Laible, S.; Bohlmann, K.; Zell, A. Plant species classification using a 3D LIDAR sensor and machine learning. Proc. Int. Conf. Mach. Learn. Appl. ICMLA 2010, 339-345. [CrossRef]

13. Nørremark, M.; Griepentrog, H.W.; Nielsen, J.; Søgaard, H.T. The development and assessment of the accuracy of an autonomous GPS-based system for intra-row mechanical weed control in row crops. Biosyst. Eng. 2008, 101, 396-410. [CrossRef]

14. Reiser, D.; Martín-López, J.; Memic, E.; Vázquez-Arellano, M.; Brandner, S.; Griepentrog, H. 3D imaging with a sonar sensor and an automated 3-axes frame for selective spraying in controlled conditions. J. Imaging 2017, 3, 9. [CrossRef]

15. Tillett, N.D.; Hague, T.; Grundy, A.C.; Dedousis, A.P. Mechanical within-row weed control for transplanted crops using computer vision. Biosyst. Eng. 2008, 99, 171-178. [CrossRef]

16. Astrand, B.; Baerveldt, A.J. An agricultural mobile robot with vision-based perception for mechanical weed control. Auton. Robots 2002, 13, 21-35. [CrossRef] 
17. Cloutier, D.C.; Van der Weide, R.Y.; Peruzzi, A.; Leblanc, M.L. Mechanical weed management. Non Chem. Weed Manag. 2007, 111-134. [CrossRef]

18. Griepentrog, H.W.; Nørremark, M.; Nielsen, J. Autonomous intra-row rotor weeding based on GPS. In Proceedings of the 2006 CIGR World Congress Agricultural Engineering for a Better World, Bonn, Germany, 3-7 September 2006; pp. 2-6.

19. Lee, W.S.; Slaughter, D.C.; Giles, D.K. Robotic weed control system for tomatoes. Precis. Agric. 1999, 1, 95-113. [CrossRef]

20. Slaughter, D.C.; Giles, D.K.; Downey, D. Autonomous robotic weed control systems: A review. Comput. Electron. Agric. 2008, 61, 63-78. [CrossRef]

21. Ge, Z.; Wu, W.; Yu, Y.; Zhang, R. Design of mechanical arm for laser weeding robot. In Proceedings of the 2nd International Conference on Computer Science and Electronics Engineering (CSE 2013), Los Angeles, CA, USA, 1-2 July 2013; pp. 2340-2343.

22. Blackmore, B.S.; Griepentrog, H.W.; Fountas, S.; Gemtos, T.A. A specification for an autonomous crop production mechanization system. Agric. Eng. Int. CIGR Ej. 2007, IX. [CrossRef]

23. Bechar, A.; Vigneault, C. Agricultural robots for field operations: Concepts and components. Biosyst. Eng. 2016, 149, 94-111. [CrossRef]

24. Anatis The Robotic in Support of the Environmental Friendly Agriculture! The Only Robot for Hoeing and Aid with Decision Making. Available online: http:/ /www.trp.uk.com/trp/uploads/carrebrochures/023_ Anatis\%20-\%20GB.pdf (accessed on 9 January 2019).

25. Zhang, C.; Li, N. System Integration Design of Intra-Row Weeding Robot; ASABE: Saint Joseph, MI, USA, 2013.

26. Contente, O.M.D.S.; Lau, J.N.P.N.; Morgado, J.F.M.; Santos, R.M.P.M. Dos vineyard skeletonization for autonomous robot navigation. In Proceedings of the 2015 IEEE International Conference on Autonomous Robot Systems and Competitions (ICARSC 2015), Villa Real, Portugal, 8-10 April 2015; pp. 50-55. [CrossRef]

27. Igawa, H.; Tanaka, T.; Kaneko, S.; Tada, T.; Suzuki, S. Visual and tactual recognition of trunk of grape for weeding robot in vineyards. In Proceedings of the 35th Annual Conference of the Industrial Electronics Society (IECON 2009), Porto, Portugal, 3-5 November 2009; pp. 4274-4279. [CrossRef]

28. Velicka, R.; Mockeviciene, R.; Marcinkeviciene, A.; Pupaliene, R.; Kriauciuniene, Z.; Butkeviciene, L.M.; Kosteckas, R.; Cekanauskas, S. The effect of non-chemical weed control on soil biological properties in a spring oilseed rape crop. Zemdirb. Agric. 2017, 104, 107-114. [CrossRef]

29. Sick AG Waldkirch Operating Instructions LMS1xx. Available online: https://mysick.com/saqqara/ im0031331.pdf (accessed on 11 January 2017).

30. Vectornav VN-100 IMU/AHRS High-Performance Embedded Navigation. Available online: https:/ / www.vectornav.com/docs/default-source/documentation/vn-100-documentation/PB-120002.pdf?sfvrsn=9f9fe6b9_16 (accessed on 1 December 2017).

31. Microsonic Datasheet pico+100/U. Available online: https://www.microsonic.de/DWD/_111327/pdf/ 1033/microsonic_pico+100_U.pdf (accessed on 9 January 2019).

32. Quigley, M.; Conley, K.; Gerkey, B.; Faust, J.; Foote, T.; Leibs, J.; Berger, E.; Wheeler, R.; Mg, A. ROS: An open-source robot operating system. In Proceedings of the 2009 ICRA Workshop on Open Source Software, Kobe, Japan, 12-17 May 2009; Volume III, p. 5.

33. Foote, T. Tf: The transform library. In Proceedings of the 2013 IEEE Conference On Tehnologies for Practical Robot Applications (TePRA), Woburn, MA, USA, 22-23 April 2013.

34. Fischler, M.A.; Bolles, R.C. Random sample consensus: A paradigm for model fitting with applications to image analysis and automated cartography. Commun. ACM 1981, 24, 381-395. [CrossRef]

35. Software, I. Open Source Software ImageJ. Available online: https://imagej.net/Welcome (accessed on 29 October 2018).

(C) 2019 by the authors. Licensee MDPI, Basel, Switzerland. This article is an open access article distributed under the terms and conditions of the Creative Commons Attribution (CC BY) license (http:/ / creativecommons.org/licenses/by/4.0/). 